\title{
Lymphatic filariasis in Luangwa District, South-East Zambia
}

\author{
Sheila Tamara Shawa', Enala T Mwase ${ }^{1}$, Erling M Pedersen² and Paul E Simonsen ${ }^{2 *}$
}

\begin{abstract}
Background: Past case reports and recent data from LF mapping surveys indicate that LF occurs in Zambia, but no studies have been carried out to document its epidemiology and health implications. The present study assessed infection, disease, transmission and human perception aspects of LF in an endemic area of Luangwa District, South-East Zambia, as a background for planning and implementation of control.

Methods: Two neighbouring rural communities were registered and a questionnaire survey undertaken. Clinical examination, and sampling of blood for circulating filarial antigens (CFA; marker of adult worm infection) and antibodies to Bm14 antigen (marker of exposure to transmission), were carried out during the daytime. Blood from CFA positive individuals was examined for microfilariae $(\mathrm{mf})$ at night. Vector surveys were carried out in selected households, using light traps.

Results: 985 individuals aged $\geq 1$ year were registered. The CFA prevalence increased with age from $1.2 \%$ in age group 1-14 years to $20.6 \%$ in age group $50+$ years (overall $8.6 \%$ ). Wuchereria bancrofti mf were identified in $10.9 \%$ of CFA positive individuals (corresponding to a community prevalence of $0.9 \%$ ). Prevalence and intensity of Bm14 antibodies were much higher in individuals $\geq 30$ years than in younger individuals (57.2 vs. 19.3\%; 0.594 vs. 0.241 OD-values). Elephantiasis and hydrocele were well known clinical manifestations in the area, but only one case of hydrocele was detected in the study population. Identified potential vectors were Anopheles funestus and An. gambiae.
\end{abstract}

Conclusion: The study confirmed that LF was endemic in the study communities, but infection and disease prevalence was low. Several indications, including a marked recent decline in CFA prevalence, suggest that transmission in the area is on the decrease, perhaps because of intensive application of malaria control measures targeting the Anopheles vectors. It is recommended that mass drug administration is initiated to accelerate this positive trend of decline in LF transmission in the area.

Keywords: Lymphatic filariasis, Wuchereria bancrofti, Circulating filarial antigens, Antibodies to Bm14, Microfilariae, Vector mosquitos, Human perception, Epidemiology, Zambia

\section{Background}

Many parts of Sub-Saharan Africa are known to be endemic for lymphatic filariasis (LF) [1], and detailed studies on the epidemiology and health implications of LF have been documented from several countries in this region. However, except for results from recent field surveys in Malawi [2-4] and a socio-environmental study on transmission risk in northern Mozambique [5], knowledge on LF

\footnotetext{
* Correspondence: pesi@sund.ku.dk

${ }^{2}$ Department of Veterinary Disease Biology, Faculty of Health and Medical Sciences, University of Copenhagen, Thorvaldsensvej 57, 1871

Frederiksberg C, Denmark

Full list of author information is available at the end of the article
}

infection, disease and transmission patterns in the central and southern region of Africa is limited. Available information from case reports and historic surveys indicate, though, that LF has a wider distribution in this part of Africa [6-9].

According to Buckley [10], the first cases of Wuchereria bancrofti microfilaraemia in Zambia were reported in 1938, and while undertaking a survey on human helminth infections in the northern and central part of the country, he recorded a few more cases. However, it was difficult to rule out the possibility of LF having been acquired elsewhere as the infected individuals were either not permanent residents in Zambia or had travelled to LF endemic

\section{Biomed Central}

(c) 2013 Shawa et al.; licensee BioMed Central Ltd. This is an open access article distributed under the terms of the Creative Commons Attribution License (http://creativecommons.org/licenses/by/2.0), which permits unrestricted use, distribution, and reproduction in any medium, provided the original work is properly cited. 
neighbouring countries. He also indicated that there was evidence of LF infections being seen in Luangwa District (previously Feira District), and that clinical cases of elephantiasis - locally known as "Serenje leg" or "Feira Leg" were seen in some districts of the country.

A small night blood survey carried out later in the Luangwa basin (Central Province) did not identify any microfilariae of W. bancrofti [11]. However, in 1975, Hira reported the first definite autochthonous case of $W$. bancrofti infection in a fisherman from Luangwa District who had never left Zambia [12,13]. Additional cases of LF infection, including autochthonous, were reported thereafter by Hira $[13,14]$. More recently, two cases of LF infection were reported from a 22 year old male and a 46 year old female from the southern and northern parts of the country, respectively $[15,16]$. In both cases microfilariae were identified in blood smears, and in the second case the female had elephantiasis suspected to be due to the $W$. bancrofti infection.

Despite these case reports from various parts of the country, very little is known about the epidemiology and health implications of LF in Zambia. Country-wide mapping of LF was undertaken between 2003 and 2011 and indicated that LF was widespread, although in most areas with relatively low prevalence [17]. As a partner in the Global Programme to Eliminate LF, Zambia is committed to eliminate LF as a public health problem. However, for planning and implementation of successful control, it is important to have a thorough knowledge about the local epidemiological characteristics of LF. The present study assessed infection, disease, transmission and human perception aspects of LF in an endemic area of Luangwa District, South-East Zambia.

\section{Methods}

Study sites

The study was carried out in Luangwa District (formerly Feira District) in South-East Zambia. The district is located in the Rift Valley, at the confluence of the Zambezi and Luangwa rivers at altitudes below $600 \mathrm{~m}$ above sea level. There are three main seasons: a cold season from May to August (temperature range $6-26^{\circ} \mathrm{C}$ ), a hot season from September to October $\left(17-35^{\circ} \mathrm{C}\right)$ and a rainy season from November to April $\left(14-30^{\circ} \mathrm{C}\right)$. The main source of livelihood in the district is fishing on the rivers, production of reed mats and subsistence farming. The main cash crops are maize, groundnut, sweet potatoes, baobab fruit and pumpkins, and the common livestock are goats and chickens.

A study site was identified based on findings from an LF mapping survey carried out in the area in 2003, when adults from the village of Janeiro, located approximately $35 \mathrm{~km}$ north of Luangwa town, were found to have a circulating filarial antigen (CFA) prevalence of 33.3\% [17].
Janeiro (-15 $26^{\prime} 38 \mathrm{~S}, 30^{\circ} 21^{\prime} 31 \mathrm{E}$; altitude about $360 \mathrm{~m}$ ) and its neighbouring village Yapite, with a combined population of approximately 1000 individuals, were selected for the present study (Figure 1). The two villages comprised a continuous stretch of scattered households along Rufunsa River (a tributary to Luangwa River) resembling each other closely in all ecological, cultural and household activity aspects, and were considered one study population for the purpose of the present study. Rufunsa River is a source of water for both villages for bathing, washing and other activities such as collection of reeds for making mats. The river also serves as a breeding site for mosquitos except during the dry season when the water dries up. Each of the villages had a health post.

\section{Study design}

The study was cross-sectional. A house to house census was carried out in the study population in April/May 2011 during which the name, age and sex of individuals aged 1 year and above were registered. At the same time, a questionnaire survey was undertaken among individuals aged 15 years and above, who were present during the registration and accepted to take part. The survey captured information regarding presence of chronic LF disease (elephantiasis and hydrocele) in Luangwa District, attitudes and practices towards this disease, and possession and use of mosquito bed nets in the community. After the interview, information was given about LF and its transmission, treatment and prevention, and all household individuals aged 1 year and above were requested to come for examination at the health post.

Examination of blood for CFA (a marker of presence of adult W. bancrofti worms $[18,19]$ ) and collection of blood on filter paper for antibodies to Bm14 (a marker of exposure to transmission [20]) was carried out during the day at the health post. Individuals aged 15 years and above were examined clinically for chronic manifestations of LF. Individuals found positive for CFA were asked to come back to the health post between 21:30 and 01:00 hours for blood sampling for microfilaria investigation, due to the nocturnal periodicity of the microfilariae. Vector surveys were carried out in selected households after completion of the human surveys.

Ethical approval and research clearance for the study was provided by the University of Zambia Research and Ethics Committee. Permission was provided by the Ministry of Health, the Provincial and District Health office, the District Commissioner's office, the local area chief and the village headmen. The objectives, requirements, benefits and duration of the study were explained to the villagers in the local language (Chikunda). LF leaflets and information sheets were also distributed. Verbal consent was obtained from all individuals before they participated in the examinations. Consent for individuals aged 15 years and below was 


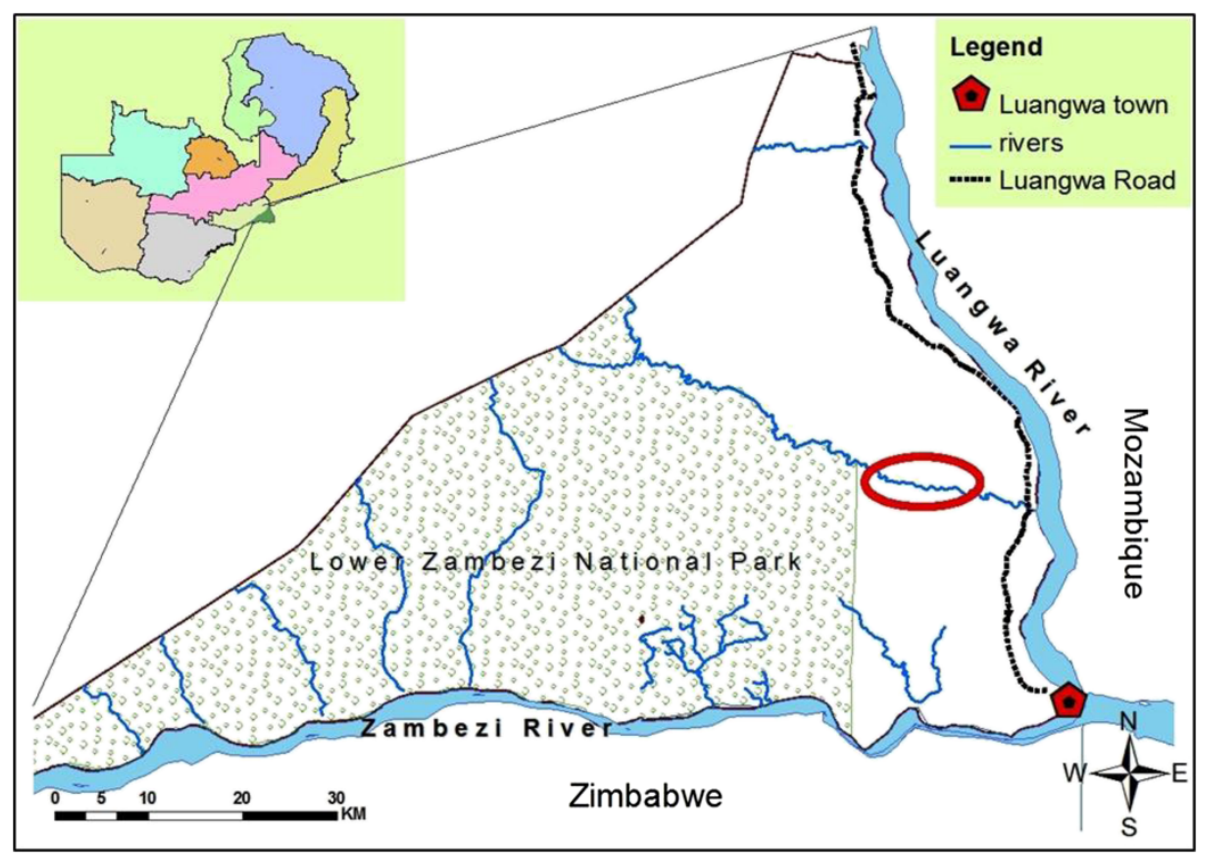

Figure 1 Map showing the location of the study site in Luangwa District. Red circle indicates location of households inhabited by the study population. Upper left corner shows the provinces in Zambia, and the location of Luangwa District in Lusaka Province.

given by parents/guardians. Children who were unwilling to take part in the study despite their parents/guardians consent were not included.

\section{Human examinations}

Individuals aged 1 year and above were tested for CFA by use of Binax NOW Filariasis immunochromatographic test (ICT) cards (Inverness Medical Innovations, Maine, USA) according to manufacturer's instructions. The results were read exactly 10 minutes after application of blood to the cards. A single band was interpreted as a negative result and two bands as a positive result.

Immediately following the CFA examination, additional $60 \mu \mathrm{l}$ (6 drops of $10 \mu \mathrm{l}$ ) of finger prick blood was applied on filter paper blood collection discs (TropBio Pty Ltd, Townsville, Australia) according to instructions from the manufacturer. Each protrusion on the disc was saturated with blood from the same individual. The filter papers were left to dry thoroughly and then placed individually in small plastic bags and kept frozen at $-20^{\circ} \mathrm{C}$.

A clinician examined individuals aged 15 years and above for chronic manifestations of LF (elephantiasis and hydrocele). Manifestations were graded as previously described [21,22].

Individuals found positive for CFA were requested to meet the study team at the health post in the evening for microfilaria $(\mathrm{mf})$ examination by use of the counting chamber technique [23]. Between 21:30 and 01.00 hours, $100 \mu \mathrm{l}$ of blood was collected from a finger prick into a heparinised capillary tube and immediately transferred into specimen tubes with $1 \mathrm{ml}$ of $3 \%$ acetic acid. The specimens were later examined in a counting chamber under a compound microscope, and the number of mf counted. Immediately after the first night blood sample, thick blood smears were prepared from the same individuals for accurate $\mathrm{mf}$ species identification and photography. The smears were de-haemoglobinized, fixed in methanol, stained with Giemsa and examined under a compound microscope.

\section{Vector surveys}

Eight households with at least one individual found positive for CFA were selected for mosquito surveys that were carried out on 10 consecutive nights. Individuals sleeping in the collection room were provided with a rectangular un-impregnated mosquito bed net. A CDC miniature light trap (Model 512, John W. Hock Company, Florida, USA) was hung outside one of the nets, slightly above the head position of the person sleeping in the bed. The traps were turned on at 18.00 hours and off at 06.00 hours the following morning [24]. Trapped mosquitoes were transferred with an aspirator to paper cups covered with netting material. A cotton pad soaked in $10 \%$ glucose was placed on top of the netting material to allow mosquitos to feed while being transported. The cups were placed in a cool box and transferred to the field laboratory, where the mosquitoes were identified by morphological criteria.

The first vector survey was carried out in May 2011, but very few mosquitoes were caught. Two other similarly 
designed surveys were, therefore, carried out in August 2011 (with no mosquitoes caught) and March 2012.

\section{Laboratory examination for antibodies to $\mathrm{Bm} 14$}

The frozen filter paper blood collection discs were brought to room temperature. One of the circular protrusions from each disc, containing approximately $10 \mu \mathrm{l}$ of dried blood, was cut off and placed in an Eppendorf tube with $500 \mu \mathrm{l}$ of extraction buffer and the sample was kept in a refrigerator at $4-6^{\circ} \mathrm{C}$ overnight for antibodies to elute.

The samples were thereafter analysed for IgG4 to the recombinant antigen Bm14 by enzyme linked immunosorbent assay (ELISA) by using the commercially available CELISA Bm14 kit (Cellabs Pty Ltd, Brookvale, Australia). Analyses were performed according to manufacturer's instructions and as described elsewhere [25,26]. Negative and positive controls were prepared by adding $5 \mu$ of the concentrated controls from the kit to $495 \mu \mathrm{l}$ of extraction buffer in Eppendorf tubes. An ELISA reader (Thermo Scientific Multiskan FC spectrophotometer, Thermo Fischer Scientific Oy, Vantaa, Finland) was used to read the plates at dual wavelength of $450 / 620 \mathrm{~nm}$, and the optical density (OD) was calculated by using the ELISA reader software. Each sample was tested in duplicate and the mean OD-value was recorded as the individuals' result. Individuals with an ODvalue $\geq 0.40$ were considered antibody positive.

\section{Data analysis}

Data were entered in Epi data (version 3.1), transported to Excel for cleaning and storage and finally exported to STATA (version 12) for analysis. Geometric mean intensities (GMIs) of Bm14 OD-values were calculated as antilog $\left[\left(\sum \log x+1\right) / n\right]-1$, with $\mathrm{x}$ being the OD-values and $n$ the number of individuals included in the calculation. Categorical variables were compared by Chi-square $\left(x^{2}\right)$ test, whereas continuous variables were compared by Student's t-test. Pvalues less than 0.05 were considered statistically significant.

\section{Results}

\section{Study population}

A total of 985 individuals were registered in the two neighbouring study communities (Table 1). There were slightly more females (51.4\%) than males (48.6\%). The gender distribution in the four age groups was relatively equal with the exception of the oldest (50+ years), which had considerably more females than males. The study communities had 205 registered households, thus giving a mean number of individuals per household of 4.8 (range 1-11).

\section{Circulating filarial antigens}

546 individuals (55.4\% of those registered) were tested for CFA (Table 1). Of these, 47 were positive (overall CFA prevalence of $8.6 \%$ ). The prevalence increased with age from $1.2 \%$ in the $1-14$ years age group to $20.6 \%$ among
Table 1 Registered study population in Luangwa District and circulating filarial antigen (CFA) status among those examined

\begin{tabular}{|c|c|c|c|c|}
\hline \multirow{2}{*}{$\begin{array}{l}\text { Age } \\
\text { group } \\
\text { (years) }\end{array}$} & \multicolumn{2}{|c|}{ Study population } & \multicolumn{2}{|c|}{ CFA } \\
\hline & Total & Female: male ratio & No. examined & No. positive (\%) \\
\hline $1-14$ & 473 & 0.89 & 248 & $3(1.2)$ \\
\hline $15-29$ & 241 & 1.25 & 138 & $15(10.9)$ \\
\hline $30-49$ & 156 & 0.95 & 92 & $15(16.3)$ \\
\hline $50+$ & 115 & 1.73 & 68 & $14(20.6)$ \\
\hline Total & 985 & 1.06 & 546 & 47 (8.6) \\
\hline
\end{tabular}

those aged 50 years and more (Figure 2). The CFA prevalence in the $15+$ years and $30+$ years age groups was significantly higher than in individuals below these ages ( $14.8 \%$ vs. $1.2 \%$ and $18.1 \%$ vs. $4.7 \%$; $\mathrm{X}^{2}$ test, $\mathrm{P}<0.001$ for both tests). It was slightly but not significantly higher in males than in females $\left(9.3 \%, \mathrm{n}=248\right.$ vs. $8.1 \%, \mathrm{n}=298$; $\mathrm{X}^{2}$ test, $\mathrm{P}>0.05$ ).

\section{Microfilariae}

Night blood samples were collected from 46 of the 47 individuals found positive for CFA. Among these, 5 (10.9\%) were positive for $\mathrm{mf}$ with the counting chamber technique. They were aged 27 (male), 47 (male), 49 (male), 50 (female) and 83 (male) years and had intensities of 1, 9, 11,16 and $19 \mathrm{mf} / 100 \mu \mathrm{l}$ of blood, respectively. On the assumption that the $5 \mathrm{mf}$ positive individuals were the only mf positive individuals among the 546 CFA examined individuals, the $\mathrm{mf}$ prevalence among the CFA examined individuals was $0.9 \%$, and among the 298 CFA examined individuals aged $\geq 15$ years it was $1.7 \%$.

Thick blood smears were prepared from 25 of the 46 individuals examined with the counting chamber technique, and $\mathrm{mf}$ were found in smears from three of these. All three had also been found positive for $\mathrm{mf}$ using the counting chamber technique. The $\mathrm{mf}$ in the smears were identified

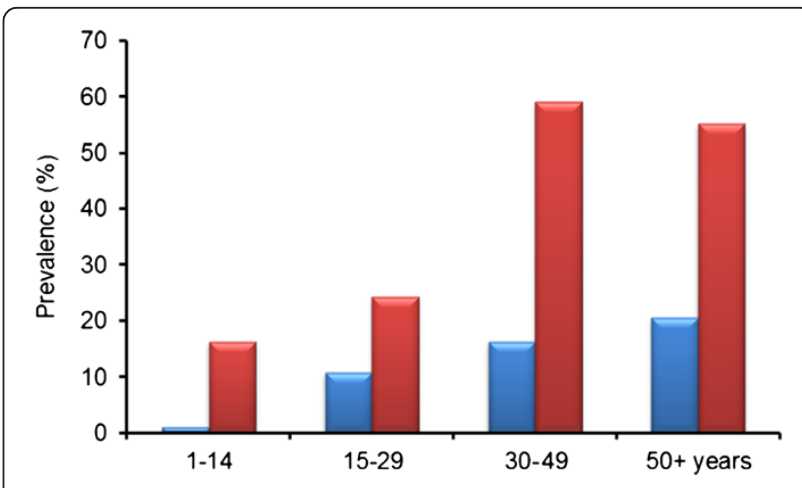

Figure 2 Prevalence of circulating filarial antigens (blue bars) and antibodies to $\mathrm{Bm} 14$ (red bars) in relation to age group in the study population in Luangwa District. 
as W. bancrofti on the basis of their graceful curves, pointed tails, lack of terminal nuclei and a clearly visible sheath protruding from both ends (Figure 3).

\section{Clinical findings}

CFA examined individuals aged 15 years and above were also clinically examined for chronic manifestation of LF, namely 183 females and 115 males. No cases of elephantiasis were seen and only one male had hydrocele grade 2 (54 years, CFA negative).

\section{Antibodies to Bm14}

The majority (538 or $98.5 \%$ ) of CFA examined individuals were also examined for antibodies to Bm14 (Table 2). Of these, 164 were positive thus giving an overall Bm14 prevalence of $30.5 \%$. The prevalence was lowest (16.4\%) in the 1-14 years age group (Figure 2) and it was significantly higher in individuals aged $30+$ years than in those below this age $\left(57.2 \%\right.$ vs. $19.3 \%, x^{2}$ test, $\left.\mathrm{P}<0.001\right)$. It was slightly but not significantly higher in males than in females (34.0\%, $\mathrm{n}=247$ vs. $27.5 \%, \mathrm{n}=291 ; \mathrm{X}^{2}$ test, $\left.\mathrm{P}>0.05\right)$.

When analysed for the same 538 individuals, the GMI of antibodies to Bm14 in general followed the same patterns as the prevalence. Thus, the lowest GMI was seen in the youngest age group (Table 2), and it was significantly higher in those aged 30+ years than in those below this age (0.5942 vs.0.2407 OD-values; t-test, $\mathrm{P}<0.001)$. When analysed for the $164 \mathrm{Bm} 14$ positive individuals, a similar pattern of GMIs was seen (Table 2), although as expected the levels were higher than for GMIs among all examined. The GMI among positive individuals was significantly higher in those aged 30+ years compared to those below this age (1.0139 vs. $0.8202 \mathrm{OD}$-values; t-test, $\mathrm{P}=0.017)$.

\section{Relationship between CFA, antibodies to Bm14, mf and} clinical manifestations

The relationship between CFA status and antibodies to Bm14 was analysed for the 538 individuals examined for
Table 2 Antibodies to Bm14 among examined individuals in the study population in Luangwa District

\begin{tabular}{lcccc}
\hline $\begin{array}{l}\text { Age group } \\
\text { (years) }\end{array}$ & $\begin{array}{c}\text { No. } \\
\text { examined }\end{array}$ & $\begin{array}{c}\text { No. } \\
\text { positive (\%) }\end{array}$ & $\begin{array}{c}\text { GMI* } \\
\text { among all }\end{array}$ & $\begin{array}{c}\text { GMI* } \\
\text { among positives }\end{array}$ \\
\hline $1-14$ & 244 & $40(16.4)$ & 0.2157 & 0.7550 \\
$15-29$ & 135 & $33(24.4)$ & 0.2874 & 0.9025 \\
$30-49$ & 92 & $54(58.7)$ & 0.6167 & 1.0188 \\
$50+$ & 67 & $37(55.2)$ & 0.5638 & 1.0068 \\
Total & 538 & $164(30.5)$ & 0.3361 & 0.9253 \\
\hline
\end{tabular}

*) Geometric mean intensity, in OD-values.

both of these markers (Table 3). The prevalence of antibodies to Bm14 was significantly higher among CFA positive than among CFA negative individuals (57.4\% vs. $27.9 \%$; $\chi^{2}$ test, $\left.\mathrm{P}<0.001\right)$. The GMI of OD-values was also significantly higher among CFA positive individuals than among those negative for CFA, both when calculated on the basis of all examined (0.6989 vs. 0.3143 OD-values; t-test, $\mathrm{P}<$ 0.001 ) and of Bm14 positives only (1.2628 vs. 0.8649 ODvalues; t-test, $\mathrm{P}<0.001)$.

All five individuals with $\mathrm{mf}$ were positive for CFA, but only three of these were positive for antibodies to Bm14. The single male with hydrocele was positive for antibodies to Bm14 but negative for CFA and $\mathrm{mf}$.

\section{Questionnaire survey}

262 individuals aged 15 years and above (51.2\% of those registered) took part in the questionnaire surveys (Table 4). The majority indicated they had seen cases of elephantiasis (79\%; locally called Nsakasa) and hydrocele (75.5\%; locally called Nchofu, Nthumbo or Pholo) in Luangwa district. A significantly higher percentage of individuals aged $30+$ years compared to those below this age had seen cases of elephantiasis $(83.3 \%$ vs. $72.0 \%$; $\chi^{2}$ test, $\left.\mathrm{P}=0.029\right)$ and hydrocele $\left(80.2 \%\right.$ vs. $67.7 \% ; \chi^{2}$ test, $\mathrm{P}=0.022)$. Despite the high level of recognition of these manifestations, only $29.0 \%$ and $27.1 \%$ indicated that
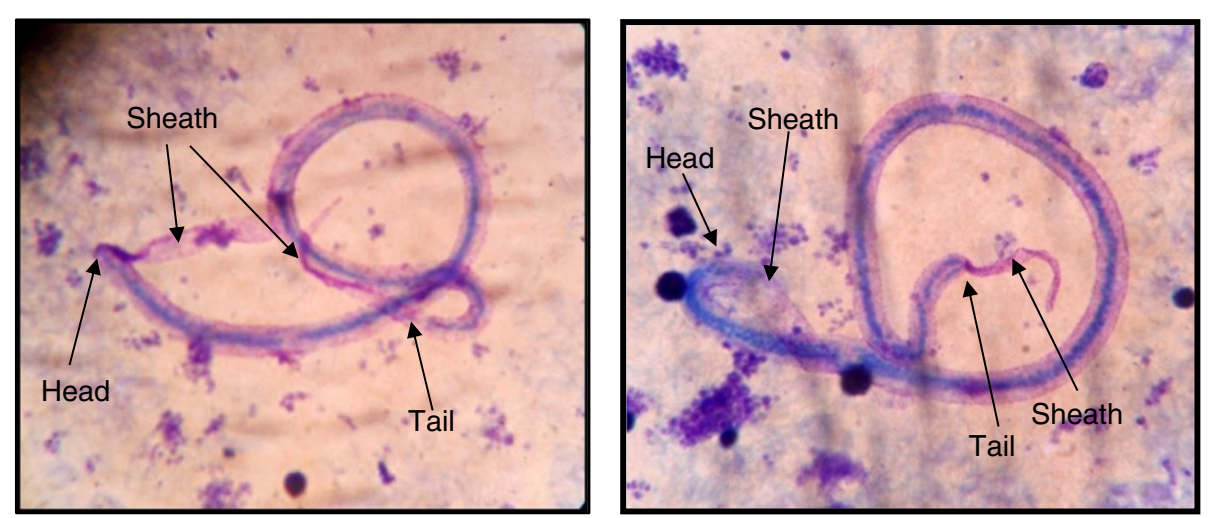

Figure 3 Photographs of two microfilariae of $w$. bancrofti in thick blood smears stained with Giemsa. The smears were prepared with blood from mf positive individuals from the study population in Luangwa District. Arrows point to characteristic features. 
Table 3 Relationship between circulating filarial antigen (CFA) status and antibodies to $\mathrm{Bm} 14$ in individuals examined for both markers in the study population in Luangwa District

\begin{tabular}{lcccc}
\hline $\begin{array}{l}\text { CFA } \\
\text { status }\end{array}$ & $\begin{array}{c}\text { No. } \\
\text { examined }\end{array}$ & $\begin{array}{c}\text { No. Bm14 } \\
\text { positive (\%) }\end{array}$ & $\begin{array}{c}\mathrm{GM}^{*} \text { of Bm14 } \\
\text { among all }\end{array}$ & $\begin{array}{c}\mathrm{GMI}^{*} \text { of Bm14 } \\
\text { among positives }\end{array}$ \\
\hline+ & 47 & $27(57.4)$ & 0.6989 & 1.2628 \\
- & 491 & $137(27.9)$ & 0.3143 & 0.8649 \\
All & 538 & 164 & 0.3361 & 0.9253 \\
\hline
\end{tabular}

*) Geometric mean intensity, in OD-values.

elephantiasis and hydrocele, respectively, was acquired from mosquito bites. Individuals with elephantiasis and hydrocele were generally indicated to be perceived as everyone else $(50 \%$ and $49.6 \%$, respectively) or with compassion (33.2\% and $33.9 \%$, respectively).

$62.2 \%$ of the respondents indicated they had a mosquito bed net at home. Possession of nets was significantly more common among respondents aged 30+ years compared to those below this age $(68.6 \%$ vs. $54.5 \%$; $X^{2}$ test, $\left.P=0.023\right) .69 .9 \%$ of those who possessed bed nets reported using them always, $25.2 \%$ sometimes and $4.9 \%$ rarely.

\section{Vector surveys}

During the three vector surveys a total of 940 mosquitoes were caught, namely 123 (13.1\% of total) during May 2011, 0 during August 2011 and 817 (86.9\% of total) during March 2012 (Table 5). Among the three well known vectors of LF in Sub-Saharan Africa, $A n$. gambiae (3.9\% of total) and An. funestus (28.6\% of total) were caught, but no $C x$. quinquefasciatus. Among the potential vectors, $A n$. funestus was much more common than An. gambiae ( $87.9 \%$ vs. $12.1 \%)$. Mosquitoes were not dissected for filarial infection, as the low mf prevalence in the humans population made it unlikely to find infected specimens.

\section{Discussion}

As a partner in the Global Programme to Eliminate LF, Zambia is committed to national elimination of LF as a public health problem. Knowledge about the distribution, prevalence and other epidemiological characteristics of LF infection and disease is important for this endeavour to become successful. Country wide mapping commenced in 2003 and was completed in 2011 [17]. 78\% of the numerous survey sites throughout the country were positive for CFA, with prevalences ranging from $1 \%$ to more than $50 \%$. However, in general, prevalences were low and only at a few sites greater than $15 \%$. Luangwa was among the districts with higher CFA prevalences, namely $25.0 \%$, $33.0 \%$ and $36.3 \%$ at the three survey sites, and was therefore selected for further studies on the epidemiological characteristics of LF infection and disease.

Table 4 Responses from questionnaire-based assessment of the occurrence and naming of elephantiasis and hydrocele in the study population in Luangwa District

Is this condition (hydrocele)* found in Luangwa District? $(n=261)$

Yes

$197(75.5)$

No

What is elephantiasis called in your local language? $(n=262)$

Nsakasa

$209(79.8)$

Other

$12(4.5)$

Don't know

$41(15.7)$

What is hydrocele called in your local language?

$(n=262)$

Nchofu

$56(21.4)$

Ntumbo

$37(14.1)$

Pholo

$19(7.2)$

Other

$19(7.3)$

Don't know

$131(50.0)$

How does one get elephantiasis? ( $n=262)$

Mosquito bite 76 (29.0)

Witchcraft

$45(17.2)$

Walking barefoot

$25(9.5)$

Sexually transmitted

$19(7.3)$

Other

$12(4.6)$

Don't know

$85(32.4)$

How does one get hydrocele? $(n=262)$

Mosquito bite $\quad 71(27.1)$

Witchcraft $30(11.5)$

Sexually transmitted $\quad 30(11.5)$

Inherited 18 (6.9)

Walking barefoot $13(4.9)$

Other 25 (9.5)

Don't know

$75(28.5)$

How are individuals with elephantiasis perceived? ( $n=262)$

Same as everyone $131(50.0)$

Compassion 87 (33.2)

Other 17 (6.5)

Don't know $27(10.3)$ 
Table 4 Responses from questionnaire-based assessment of the occurrence and naming of elephantiasis and hydrocele in the study population in Luangwa District (Continued)

$\begin{array}{ll}\text { How are individuals with hydrocele perceived? }(n=262) & \\ \text { Same as everyone } & 130(49.6) \\ \text { Compassion } & 89(33.9) \\ \text { Other } & 14(5.4) \\ \text { Don't know } & 29(11.1)\end{array}$

$\mathrm{n}$ indicates total number of individuals responding.

*) Photograph of manifestation shown.

The study was undertaken in the two neighbouring villages of Janeiro and Yapite. Households were sparsely distributed with most of them located in close proximity to the river. Some individuals including school children had to cross the river on a daily basis for school or other activities. Among the registered individuals the female: male ratio was almost equal, although the $50+$ years age group comprised mainly of elderly women who were widowed. Only about half of the registered population was examined for CFA. Many individuals did not agree to have their blood drawn for religious reasons, others were at their temporal homes located near the fields harvesting their crops, and some refused to participate due to fear of being tested for HIV.

Detection of CFA by use of ICT test cards was used in the initial screening of individuals for LF. This diagnostic test is sensitive and specific, can be used at any time of day and allows for large numbers of individuals to be screened in a short period of time $[18,19]$. The prevalence of CFA was relatively low in young individuals and increased with age, as also seen in other endemic areas [27,28]. However, the overall CFA prevalence in the study population was low ( $14.8 \%$ among those aged $\geq 15$ years), especially when considering that the prevalence reported from the same community and age group during the mapping survey eight years previously was $33.3 \%$. The marked decrease in this short period of time suggests that a recent dramatic decline in transmission had taken place. This was supported by the trend seen in CFA status among 46 re-identified community individuals who had also been examined during the mapping survey in 2003. Among 17 CFA positives in 2003, only 5 were still positive in 2011 ( $71.6 \%$ had lost infection), while among 29 CFA negatives in 2003, only one was positive in 2011 (3.4\% gain of infection). It is likely that in those who had reverted from infection positive to negative the $W$. bancrofti worms had died naturally and that no re-infection had taken place due to the low level of transmission. There were no clear gender differences in CFA prevalence, as often observed in other surveys, perhaps due to the generally low prevalence in the study community.

Many of the CFA positive individuals were negative for antibodies to $\mathrm{Bm} 14$ and vice versa, thus supporting the view that the Bm14 antibodies are not induced by the presence of adult worms but by exposure to infection $[20,29]$. Similar to CFA, the prevalence of antibodies to Bm14 also increased with increasing age. It was, however, higher than the CFA prevalence, both overall and in the individual age groups. However, whereas the increase in CFA prevalence was gradual, there was a rather abrupt increase in Bm14 prevalence, and also of Bm14 intensities, around the age of 30 years. The much higher prevalence and intensity of Bm14 in the older population might be due to differences in lifestyle, giving rise to marked differences in exposure between young and old individuals. It is also possible that it could be a reflection of a decline that has occurred in LF transmission in the more distant past, and that the older age groups had been much more exposed to filarial infection when they were young, and perhaps still sustained the Bm14 antibodies in their circulation. The significantly higher prevalence and intensity of Bm14 among the CFA positives than among CFA negatives suggests that CFA positive individuals had a higher chance of being exposed to infection than CFA negative individuals. This may not be surprising as the CFA positive group includes the $\mathrm{mf}$ positive individuals who supply infection to the vector mosquitoes and therefore keep the transmission going in their surroundings.

Mf examinations were undertaken in CFA positive individuals only, as CFA is a marker for the adult worms which produce the $\mathrm{mf}$. The prevalence of microfilaraemia was low in the study population, and the youngest individual with $\mathrm{mf}$ was 27 years old. The $\mathrm{mf}$ prevalence is generally lower than the CFA prevalence, especially in low endemicity communities, where also the first cases of $\mathrm{mf}$ are usually seen at an older age than in high endemicity communities [28]. Previous reports have noted cases of another filarial species,

Table 5 Mosquitoes caught using CDC light traps during the three surveys in the study community in Luangwa District

\begin{tabular}{lccccccc}
\hline $\begin{array}{l}\text { Survey } \\
\text { period }\end{array}$ & \multicolumn{3}{c}{ No. (\%) mosquitoes caught } & \multicolumn{1}{c}{ Total } \\
\cline { 2 - 5 } & Anopheles gambiae & Anopheles funestus & Other anophelines & Culex quinquefasciatus & Aedes spp. & Other culicines & no. caught \\
\hline May 2011 & $4(3.3)$ & $63(51.2)$ & $49(39.8)$ & $0(0.0)$ & $0(0.0)$ & $7(5.7)$ & 123 \\
August 2011 & $0(-)$ & $0(-)$ & $0(-)$ & $0(-)$ & $0(-)$ & $0(-)$ & 0 \\
March 2012 & $33(4.0)$ & $206(25.2)$ & $54(6.6)$ & $0(0.0)$ & $0(0.0)$ & $524(64.1)$ & 817 \\
All & $37(3.9)$ & $269(28.6)$ & $103(11.0)$ & $0(0.0)$ & $0(0.0)$ & $531(56.5)$ & 940 \\
\hline
\end{tabular}


Mansonella perstans, in Zambia [11,14]. However, in the present study none of the characteristic small $M$. perstans $\mathrm{mf}$ were detected with the counting chamber technique, and the $\mathrm{mf}$ in the blood smears were clearly identified as $W$. bancrofti on the basis of their morphological features.

The burden of chronic clinical LF disease was low in the study population, probably because of the general low level of endemicity [28]. This is in contrast to previous reports, which indicated that elephantiasis (Feira leg) and hydrocele were common in the area $[10,11,13]$. It might be speculated that a decrease in LF transmission in the past could have led to a reduction in the chronic disease burden. The questionnaire surveys revealed that a significantly higher proportion of individuals aged $\geq 30$ years had seen cases of elephantiasis and hydrocele in the area compared to those who were younger, thus being another indication that LF may have been more common in the past. Officers from Luangwa District Health Office and the local Katondwe Mission Hospital informed the study team that hydroceles were still common and that hydrocelectomies were frequently carried out at the hospital. However, many individuals from nearby areas in Zimbabwe and Mozambique, where LF is also endemic $[8,30]$, seek medical treatment from the mission hospital and it is likely that at least some of the hydrocele cases they report are from neighbouring countries. Despite the high percentages of questionnaire respondents who indicated to have seen cases of elephantiasis and hydrocele in the district, very few had knowledge on how these conditions were acquired; common responses included witchcraft, sexual transmission and walking barefoot (it is unlikely that the later referred to podoconiosis, a condition of endemic non-filarial elephantiasis induced by mineral particles from volcanic soils [31], as Luangwa is a lowland area with mainly alluvial soils). The responses underscored the importance of sensitization of the community populations before implementation of MDA, to ensure maximum co-operation and compliance [32].

Studies on mosquitoes and their role in malaria transmission have been carried out in some parts of Zambia [33-35] including Luangwa District [36,37], but there have been no documented studies on vectors responsible for LF transmission in the country. During the first two vector surveys of the present study very few or no mosquitos were caught, probably due to low temperatures. Several species of mosquitoes were caught during the third survey, including $A n$. funestus and An. gambiae, which are the two main LF vectors in Sub-Saharan Africa [38], including neighboring Malawi [39]. It is likely that these two species are also the main vectors of LF in Luangwa District. In agreement with other studies carried out in the same district on malaria vectors [36,37], An. funestus was much more common than An. gambiae, and this species is probably the principal LF vector in the area. Dark-pigmented $C x$. quinquefasciatus have been reported from the Southern Province of Zambia
[40], but no potential vectors of this species were caught in Luangwa District.

The questionnaire survey revealed that the majority of respondents possessed bed nets, and that most of those owning them also frequently used them. Similar high usage of bed nets has been reported previously from Luangwa District and from other parts of Zambia [41-43]. Zambia has a well-established malaria control programme, with an active integrated vector control part involving distribution of bed nets and indoor residual spraying, which has rapidly expanded the geographical coverage since 2004 [43-45]. As the vectors for malaria and LF are the same, it is likely that these malaria vector control measures have simultaneously reduced exposure to filarial parasites and could be the major course for the observed current low prevalence of LF in the study population. Vector control measures have similarly been reported to be responsible for a decline in LF prevalence in endemic communities elsewhere [46,47], and have been recommended as important additional measures for LF control [38,43].

\section{Conclusion}

The present study confirmed that LF was endemic in Luangwa District, but the burden of infection and disease was low. There were several indications that LF transmission in the area had decreased, in particular the low CFA prevalence when compared to that observed during the mapping survey eight years previously. This was likely due to a decrease in LF transmission following intensive application of malaria vector control in recent years. A very high Bm14 level in the older individuals, and a low burden of chronic LF disease compared to what was reported previously, could indicate that also a more long-term decrease in LF transmission had taken place. It is recommended that MDA is initiated to support and accelerate this positive trend of decline in LF transmission. As the neighbouring countries are also endemic for LF, a co-ordinated crosscountry approach would be most fruitful for the efforts to eliminate LF as a public health problem in the area.

\section{Competing interests \\ The authors declare that they have no competing interests.}

\section{Authors' contributions}

STS, ETM, EMP and PES conceived and designed the study. STS collected the field data under the supervision of ETM, EMP and PES. STS performed the laboratory tests, analysed the data and drafted the paper under the supervision of PES. All authors read and approved the final version of the manuscript.

\section{Acknowledgements}

The authors are grateful to the villagers from Janeiro and Yapite for participation and co-operation, to the local area chiefs for permission to undertake the study, and to the local community health workers for assistance with sensitization and census data collection. We are also grateful to the technical team from Zambia Ministry of Health (Sandie Sianongo, Patrick Mubiana and Nina Moonga), the University of Zambia (Benson Mandanda, Botha Malunda and Douglas Banda) and the University of Copenhagen (Jakob Felsager) for the skilled assistance in the field and the 
laboratory. We thank officers at Luangwa District Health Office and Health Centre for advice and assistance. The study received financial support from Danida Research Council, Denmark (FFU grant \#09-096LIFE).

\section{Author details}

'Department of Paraclinical Studies, School of Veterinary Medicine, University of Zambia, Lusaka, Zambia. ${ }^{2}$ Department of Veterinary Disease Biology, Faculty of Health and Medical Sciences, University of Copenhagen, Thorvaldsensvej 57, 1871 Frederiksberg C, Denmark.

Received: 5 July 2013 Accepted: 4 October 2013

Published: 15 October 2013

\section{References}

1. Hotez PJ, Kamath A: Neglected tropical diseases in Sub-Saharan Africa: review of their prevalence, distribution, and disease burden. PLoS Negl Trop Dis 2009, 3:e412.

2. Ngwira BMM, Jabu CH, Kanyongoloka H, Mponda M, Crampin AC, Branson $\mathrm{K}$, Alexender NDE, Fine PEM: Lymphatic filariasis in the Karonga district of Northern Malawi: a prevalence survey. Ann Trop Med Parasitol 2002, 96:137-144

3. Ngwira BMM, Tambala P, Perez AM, Bowie C, Molyneux DH: The geographical distribution of lymphatic filariasis infection in Malawi. Filaria J 2007, 6:12

4. Nielsen NO, Makaula P, Nyakuipa D, Bloch P, Nyasulu Y, Simonsen PE: Lymphatic filariasis in lower Shire, Southern Malawi. Trans R Soc Trop Med Hyg 2002, 96:133-138.

5. Manhenje I, Galan-Puchades MT, Fuentes MV: Socio-environmental variables and transmission risk of lymphatic filariasis in central and northern Mozambique. Geospat Hlth 2013, 7:391-398.

6. Sasa M: Human filariasis: A global survey of epidemiology and control. University of Tokyo Press; 1976.

7. Hawking F: The distribution of human filariasis throughout the World part III. Africa. Trop Dis Bull 1977, 74:649-679.

8. Fujita K, ODA T, Tsukidate S, Mori A, Ueda M, Kurokawa K: Preliminary report on human filariasis in Mozambique, East Africa. Trop Med 1985, 27:83-91.

9. Kelly-Hope LA, Thomas BC, Bockerie MJ, Molyneux DH: Lymphatic filariasis in the Democratic Republic of Congo; micro-stratification overlap mapping (MOM) as a prerequisite for control and surveillance. Parasit Vectors 2011, 4:178.

10. Buckley JJC: A helminthological survey in Northern Rhodesia. J Helminthol 1946, 21:111-174.

11. Barclay R: Filariasis in Luangwa basin. Med J Zambia 1971, 5:201-203.

12. Hira PR: Bancroftian filariasis in Zambia. Ann Trop Med Parasitol 1975, 69:521-522.

13. Hira PR: Bancroftian filariasis: an autochthonous case in Zambia. Med $J$ Zambia 1976, 10:160-163.

14. Hira PR: Wuchereria bancrofti: the staining of the microfilarial sheath in giemsa and haematoxylin for diagnosis. Med J Zambia 1977, 11:93-96.

15. Kaile T: Filariasis presenting as pyrexia of unknown origin in a young Zambian adult: a case report. Zambian J Med Health Sci 1998, 2:2-3.

16. Matondo AS, Lungu AG: Lymphatic filariasis in a Zambian woman: a case report. Zambian J Med Health Sci 1998, 2:55-56.

17. Mwase ET, Stensgaard AS, Msakashalo-Senkwe M, Mubila L, Mwansa J, Songolo P, Shawa ST, Simonsen PE: Mapping the geographical distribution of lymphatic filariasis in Zambia. PLoS Negl Trop Dis: . In press.

18. Weil GJ, Lammie PJ, Weiss $\mathrm{N}$ : The ICT filariasis test: a rapid-format antigen test for diagnosis of bancroftian filariasis. Parasitol Today 1997, 13:401-404.

19. Weil GJ, Ramzy RMR: Diagnostic tools for filariasis elimination programs. Trends Parasitol 2006, 23:2.

20. Tisch DJ, Bockarie MJ, Dimber Z, Kiniboro B, Tarongka N, Hazlett FE, Kastens W, Alpers MP, Kuzura JW: Mass drug administration trail to eliminate lymphatic filariasis in Papua New Guinea: changes in microfilaraemia, filarial antigen, and Bm14 antibody after cessation. Am J Trop Med Hyg 2008, 78:289-293.

21. Estambale BBA, Simonsen PE, Knight R, Bwayo JJ: Bancroftian filariasis in Kwale District of Kenya. I. clinical and parasitological survey in an endemic community. Ann Trop Med Parasitol 1994, 88:145-151.

22. Meyrowitsch DW, Simonsen PE, Makunde WH: Bancroftian filariasis: analysis of infection and disease in five endemic communities of north-eastern Tanzania. Ann Trop Med Parasitol 1995, 89:653-663.
23. McMahon JE, Marshall TF, Vaughan JP, Abaru DE: Bancroftian filariasis: a comparison of microfilariae counting techniques using counting chamber standard slide and membrane (nuclepore) filtration. Ann Trop Med Hyg 1979, 73:457-464.

24. Rwegoshora RT, Pedersen EM, Mukoko DA, Meyrowitsch DW, Masese N, Malecela-Lazaro MN, Ouma JH, Michael E, Simonsen PE: Bancroftian filariasis: patterns of vector abundance and transmission in two east African communities with different levels of endemicity. Ann Trop Med Parasitol 2005, 99:253-265.

25. Joseph HM, Melrose W: Applicacility of the filter paper technique for detection of antifilarial lgG4 antibodies using the Bm14 filariasis CELISA. J Parasitol Res 2010. Article ID 594687

26. Weil GJ, Curtis KC, Fischer PU, Won KY, Lammie PJ, Joseph H, Melrose WD, Brattig NW: A multicentre evaluation of a new antibody test kit for lymphatic filariasis employing recombinant Brugia malayi antigen Bm-14. Acta Trop 2011, 120s:s19-s22.

27. Onapa AW, Simonsen PE, Pedersen EM, Okelle DO: Lymphatic filariasis in Uganda: baseline investigations in Lira, Soroti and Katawi districts. Trans R Soc Trop Med Hyg 2001, 95:161-167.

28. Simonsen PE, Meyrowitsch DW, Jaoko WG, Malecela MN, Mukoko D, Pedersen EM, Ouma JH, Rwegoshora RT, Masese N, Magnussen P, Estambale BBA, Micheal E: Bancroftian filariasis infection, disease, and specific antibody response patterns in a high and a low endemicity community in East Africa. Am J Trop Med Hyg 2002, 66:550-559.

29. Joseph H, Maiava F, Naseri T, Silva U, Lammie P, Melrose W: Epidemiological assessment of continuing transmission of lymphatic filariasis in Samoa. Ann Trop Med Parasitol 2011, 105:567-578.

30. Roberts CJ, Whitehall J, Gelfand M: W. bancrofti in Kenyemba area. Cent Afr J Med 1973, 19:13-14.

31. Davey G, Tekola F, Newport MJ: Podoconiosis: non-infectious geochemical elephantiasis. Trans R Soc Trop Med Hyg 2007, 101:1175-1180.

32. Parker $M$, Allen $T$ : Will mass drug administration eliminate lymphatic filariasis? Evidence from northern coastal Tanzania. J Biosoc Sci 2013, 45:517-545.

33. Kent RJ: The mosquitoes of Macha, Zambia. The John Hopkins Malaria Research Institute; 2006. www.jhsph.edu/malaria.

34. Kent RJ, Thuma PE, Mrakurva S, Norris DE: Seasonality, blood feeding behaviour, and transmission of Plasmodium falciparum by Anopheles arabiensis after an extended draught in southern Zambia. Am J Trop Med Hyg 2007, 76:267-274.

35. Fornadel CM, Norris LC, Glass GE, Norris DE: Analysis of Anopheles arabiensis blood feeding behaviour in southern Zambia during the two years after introduction of insecticide-treated bed nets. Am J Trop Med Hyg 2010, 84:848-853.

36. Seyoum A, Sikaala CH, Canda J, Chinula D, Ntamatungiro AJ, Hawela M, Miller $J M$, Russell TL, Briet OJ, Killeen G: Human exposure to anopheline mosquitoes occurs primarily indoors, even for users of insecticide-treated nets in Luangwa Valley, South-east Zambia. Parasit Vectors 2012, 5:101.

37. Sikaala CH, Killeen GF, Chanda J, Chinula D, Miller JM, Rusell TL, Seyoum A: Evalutaion of alternative mosquito sampling methods for malaria vectors in lowland South-East Zambia. Parasit Vectors 2013, 6:91.

38. Bockarie MJ, Pedersen EM, White GB, Micheal E: Role of vector control in the global program to eliminate lymphatic filariasis. Ann Rev Entomol 2009, 54:469-487.

39. Merelo-Lobo RA, McCall PJ, Perez MA, Spiers AA, Mzilahowa T, Ngwire B, Molyneux DH, Donelly MJ: Identification of the vectors of lymphatic filariasis in the Lower Shire Valley, southern Malawi. Trans R Soc Trop Med Hyg 2003, 97:299-301.

40. Kent RJ, Mrakurva S, Hamapumbu H, Norris DE: Recognition of a novel melanotic mutant in a field population of Culex pipiens quinquefasciatus in southern Zambia. J Am Mosa Contr Assoc 2007, 23:71-75.

41. Chizema-Kawesha E, Miller JM, Steketee RW, Mukonka VM, Mukuka C, Mohamed AD, Miti SK, Campbell CC: Scaling up malaria control in Zambia: Progress and impact 2005-2008. Am J Trop Med Hyg 2010, 83:480-488.

42. Larsen DA, Keating J, Miller J, Bennett A, Changufu C, Katebe C, Eisele TP: Barriers to insecticide-treated mosquito net possession 2 years after a mass free distribution campaign in Luangwa District Zambia. PloS One 2010, 5:e13129.

43. Kelly-Hope LA, Molyneux DH, Bockarie MJ: Can malaria vector control accelerate the interruption of lymphatic filariasis transmission in Africa; capturing a window of opportunity? Parasit Vectors 2013, 6:39. 
44. Chanda E, Masaninga F, Coleman M, Sikaal C, Katebe C, MacDonald M, Baboo KS, Govere J, Manga L: Integrated vector management: the Zambian experience. Malaria J 2008, 7:164.

45. Chanda E, Hemingway J, Kleinschmidt I, Rehman AM, Phiri FN, Coetzer S, Mthembu D, Shinondo CJ, Chizema-Kawesha E, Kamuliwo M, Mukonka V Baboo KS, Coleman M: Insecticide resistance and the future of malaria control in Zambia. PLoS One 2011, 6:e24336.

46. Webber RH: The natural decline of Wuchereria bancrofti infection in a vector control situation in the Solomon Islands. Trans R Soc Trop Med Hyg 1977, 71:396-400

47. Njenga SM, Mwandawiro CS, Wamae CN, Mukoko DA, Omar AA, Shimada M, Bockarie MJ, Molyneux DH: Sustained reduction in prevalence of lymphatic filariasis infection in spite of missed rounds of mass drug administration in an area under mosquito nets for malaria control. Parasit Vectors 2011, 4:90

doi:10.1186/1756-3305-6-299

Cite this article as: Shawa et al:: Lymphatic filariasis in Luangwa District, South-East Zambia. Parasites \& Vectors 2013 6:299.

\section{Submit your next manuscript to BioMed Central and take full advantage of:}

- Convenient online submission

- Thorough peer review

- No space constraints or color figure charges

- Immediate publication on acceptance

- Inclusion in PubMed, CAS, Scopus and Google Scholar

- Research which is freely available for redistribution 